\title{
Title: Prospective analysis of hydrogel spacer for prostate cancer patients undergoing radiotherapy
}

Michael Chao ${ }^{(1,4)}$, FRANZCR; Huong Ho ${ }^{(1)}$, B. App. Sc., M. App Sc; Yee Chan ${ }^{(4,7)}$, FRACS; Alwin $\operatorname{Tan}^{(2)}$, FRACS; Trung Pham ${ }^{(3)}$, FRACS; Damien Bolton ${ }^{(4,7)}$, FRACS; Andrew Troy ${ }^{(4)}$, FRACS; Catherine Temelcos ${ }^{(5)}$, FRACS; Shomik Sengupta ${ }^{(4)}$, FRACS; Kevin McMillan ${ }^{(7)}$ FRACS; Chee Wee Cham $^{(1)}$, FRACS; Madalena Liu ${ }^{(7)}$, FRACS; Wei Ding ${ }^{(1)}$, M.D., M. Sc; Brindha Subramanian ${ }^{(1)}$, M. Sc., PhD; Jason Wasiak, M.PH., PhD ${ }^{(4,6)}$; Daryl Lim Joon ${ }^{(1)}$, FRANZCR; Sandra Spencer ${ }^{(1)}$, Grad Dip App Sc; Nathan Lawrenstchuk ${ }^{(4)}$, FRACS.

${ }^{(1)}$ Genesis Cancer Care Victoria, Ringwood, Australia; ${ }^{(2)}$ The Bays Hospital, Mornington, Australia; ${ }^{(3)}$ The Valley Private Hospital, Mulgrave, Australia; ${ }^{(4)}$ The Austin Hospital, Heidelberg, Australia; ${ }^{(5)}$ St Vincent's Hospital, Fitzroy, Australia; ${ }^{(6)}$ University of Melbourne, Melbourne, Australia, ${ }^{(7)}$ Ringwood Private Hospital, Ringwood East, Australia

Correspondence: Huong Ho, Genesis Cancer Care Victoria, 36 Mt Dandenong Road, Ringwood East, Victoria 3135, Australia. Email: huong.ho@genesiscare.com.au

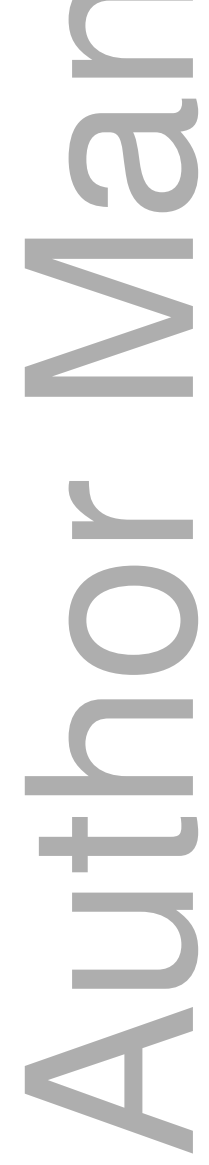

This is the author manuscript accepted for publication and has undergone full peer review but has not been through the copyediting, typesetting, pagination and proofreading process, which may lead to differences between this version and the Version of Record. Please cite this article as doi: $10.1111 /$ bju. 14192

This article is protected by copyright. All rights reserved 
MRS. HUONG HO (Orcid ID : 0000-0002-8212-4220)

DR. NATHAN LAWRENTSCHUK (Orcid ID : 0000-0001-8553-5618)

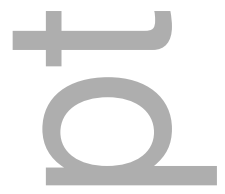

Article type : Original Article

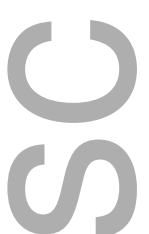

Article category: Urological Oncology

\section{Abstract}

Objective: The purpose of this study was to report on the dosimetric benefits and late toxicity outcomes following injection of a hydrogel spacer (HS) between the prostate and rectum for patients treated with prostate radiotherapy.

Methods: A total of 76 patients with a clinical stage of T1-T3a prostate cancer underwent general anaesthesia for fiducial marker insertion plus injection of the HS into the peri-rectal space prior to intensity modulated radiation therapy (IMRT) or volumetric modulated radiation therapy (VMAT). Spacer safety, dosimetric benefits and the immediate to long-term effects of gastrointestinal toxicity (GI) were assessed. Results: There were no postoperative complications reported. Mean prostate size were 66.0cc (25.0cc - 187.0cc). Rectal dose volume parameters were observed with volume of rectum receiving 70Gy $\left(\mathrm{rV}_{70}\right)$, 75Gy $\left(\mathrm{rV}_{75}\right)$ and $78 \mathrm{~Gy}\left(\mathrm{rV}_{78}\right)$ were $7.8 \%$, $3.6 \%$ and $0.4 \%$. $21 \%(16 / 76)$ developed acute grade 1 GI toxicities but all were resolved completely by 3 months post-treatment. 3\% (2/76) developed late grade 1 GI toxicities. No patients experienced acute or late grade 2+ GI toxicities.

Conclusion: Injection of HS resulted in a reduction of irradiated rectal dose volumes along with minimal GI toxicities; irrespective of prostate size

Key words: hydrogel spacer; IMRT; VMAT; prostate cancer 


\section{Introduction}

It is estimated that there will be approximately 16,665 prostate cancer diagnoses in 2017 resulting in the deaths of over 3,452 Australian men ${ }^{1}$. Radiotherapy (RT) remains a highly effective treatment for patients with localised disease. Whilst advanced RT planning techniques such as IMRT and VMAT have enabled dose escalation to the prostate and reduced toxicity, it is often associated with increased genitourinary (GU) and GI toxicities, rectal toxicity in particular. It is well documented that late rectal toxicity is correlated to the volume of the anterior rectal wall receiving higher dose especially the $\mathrm{V}_{70}{ }^{2}$. Reducing this volume being treated will minimise the rectal toxicity and one of the most simple and effective way would be to increase the distance between the rectum and the prostate.

Although recent advances in RT delivery, including image guided RT (IGRT) and IMRT and VMAT have reduced toxicity rate, it has proven a challenge to spare the anterior rectal wall. A number of different methods such as collagen, hyaluronic acid and blood patch have been explored with minimal success rate $e^{3,4,5,6}$. HS implanted between the prostate and rectum in recent years has gained noticeable interest in increasing the peri-rectal spacing and reducing radiotherapy related rectal toxicity ${ }^{7}$ either in external beam RT alone; low or high dose rate brachytherapy or combination of both external beam RT and brachytherapy ${ }^{8,9}$.

The safety and efficacy of hydrogel in prostate RT setting have been reported by several studies. More so, two systematic reviews demonstrated minimal acute and early post-RT toxicities ${ }^{10,11}$. However, as with any new technique more information is needed to verify the efficacy of HS, particularly from different regions and centres ${ }^{12,13,14}$. Therefore, this study aimed to report on our initial experience of using a HS implant for the treatment of prostate cancer.

\section{Materials and Methods}

Study design

This review of a prospectively collected dataset examined the clinical safety and efficacy of the use of HS between the prostate and rectum (SpaceOAR ${ }^{\circledR}$, Augmenix Inc., Waltham, MA, USA) for men undergoing a course of IMRT or VMAT. Our 
institution's Human Research and Ethics Committee approved our treatment protocol prior to commencement. All participants provided written medical informed consent before undergoing any therapeutic procedure.

\section{Participants}

76 confirmed prostate cancer patients from Radiation Oncology Victoria, Melbourne, Australia, were enrolled into the study from December 2013 to December 2015. Eligible patients were consecutive men $\geq 18$ years with histologically confirmed ISUP grade of $1-5^{15}$ prostate cancer and with clinically staged T1-T3aNOM0 disease receiving $78 \mathrm{~Gy}$ of prostate IMRT. The exclusion criteria included previous pelvic surgery or radiotherapy, and a history of Crohn's disease or inflammatory bowel disease.

Hydrogel implant procedure

Under general anaesthesia and with transrectal ultrasound guidance, all patients underwent transperineal insertion of three intra-prostatic gold seed markers ${ }^{7}$ followed by injection of 8-10 millimetres of HS into the anterior perirectal space between Denonvilliers' fascia and the anterior rectal wall (Fig 1.).

The HS was implanted by a single radiation oncologist (RO) specialised in prostate brachytherapy working in unison with a team of urologists. As there is no simulation available to help with training, important technical expertise of the implanted procedure was disseminated to the urologists by the RO to ensure a high quality insertion of $\mathrm{HS}^{16}$.

\section{Treatment planning}

A pelvic computed tomography (CT) scan for IMRT/VMAT treatment planning was carried out within 5 days post HS injection. All patients were scanned in the supine position with a full bladder and an empty rectum as per our departmental protocol. The treatment plans were created on the Pinnacle v. 9.8 (Philips Radiation Oncology Systems, Fitchburg, WI) treatment planning system (TPS). Clinical target volumes(CTV) comprised of prostate and seminal vesicle and were defined in concordance with FROGG consensus guidelines ${ }^{17}$. The CTV to planning target volume (PTV) expansion was $7 \mathrm{~mm}$ in all directions except posteriorly, where it was 
$5 \mathrm{~mm}$. Rectal dose constraint objectives for $\mathrm{V}_{78}, \mathrm{~V}_{75}, \mathrm{~V}_{70}, \mathrm{~V}_{60}$ and $\mathrm{V}_{50}$ were $5 \%, 15 \%$, $20 \%, 35 \%$ and $50 \%$ of the rectal volume, respectively. The radiation dose was 78 Gy in 2 Gy daily over 39 fractions.

The rectum was contoured as a whole solid structure beginning at $1.0 \mathrm{~cm}$ above the most superior level of the PTV to the anorectal junction. The HS was identified and quantified by manipulating the window values within the Pinnacle TPS. As our patient cohort did not have planning magnetic resonance imaging (MRI) scan to aid with visualization of the hydrogel, in the event of any doubt in identifying the hydrogel it was contoured as rectum. Degree of separation achieved between the anterior rectal wall and the posterior edge of prostate was quantified at apex, midgland and base. Rectal $\mathrm{V}_{78}, \mathrm{~V}_{75}, \mathrm{~V}_{70}, \mathrm{~V}_{60}$ and $\mathrm{V}_{50}$ were assessed for correlation between dosimetric endpoints and any GI toxicity.

\section{Data collection and follow-up protocol}

Patients were assessed at baseline, weekly during treatment, and at 3-, 6-, and $12-$ month follow-up visits and then annually for any GI symptoms and other adverse events and for changes in medications or interventions used to treat urinary or rectal symptoms. Toxicity assessment was evaluated and graded according to the Common Terminology Criteria for Adverse Events (CTCAE) version 4.03. Acute toxicity was defined as any toxicity occurring during or within 8 weeks of RT. Late effects were considered as events occurring $>3$ months following treatment or as an event lasting $>3$ months after treatment.

\section{Results}

\section{Patient demographics}

The 76 patients identified for the study were followed up over a two-year period, with only one patient reported lost to follow up after completing his course of RT. Our population included men with a median age of 74 years (IQR 60 to 88 years) presenting with a median PSA of 10.4 (IQR 1.1 to117). Median follow-up was 14 months (IQR 12 to 29 months), with the last patient completing treatment in February 2016. For patient demographic and disease-specific variables, see Table 1. 


\section{Rectal spacing outcomes}

Based on the CT planning data, measured perirectal spacing dimensions resulting from hydrogel injection are shown in Table 2. The average achievable spacing was very similar across the entire cohort irrespective of the prostate size.

\section{Dosimetric outcomes}

Table 3 demonstrated a mean achievable rectal dose constraints for our patient cohort with relatively low rectal dose volume in the high dose region of rectal $V_{70}$ and $V_{78}$ (Fig. 2). Most importantly, these improvements were also observed in the larger prostates as seen in Fig.3 below

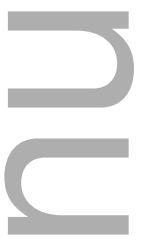

\section{Toxicity outcomes}

None of the patients reported any rectal bleeding. There were no reports of any adverse events including rectal perforation, or infection following hydrogel injection. $16(21 \%)$ patients overall developed acute grade 1 GI toxicity with all symptoms resolved within three months after completion of treatment (Tab. 4). One patient developed a late grade 1 rectal haemorrhage at 9 months post treatment, however this was due to rectal haemorrhoids. One patient developed late grade 1 proctitis at eight months post treatment. No patients developed late GI toxicity of grade $2+$.

Figure 4 is a breakdown of the incidence of acute radiation induced GI toxicity at various timepoints throughout the 8 week course of RT. As expected the incidence was greatest at the conclusion of treatment with all symptoms resolved at 3 months post RT.

$63(83 \%)$ patients developed acute grade 1 GU toxicity. These symptoms persisted in $18(24 \%)$ patients three months after completion of treatment. Two (3\%) patients developed a urinary stricture requiring intermittent self-catheterisation (Tab. 5). 


\section{Discussion}

Progress in radiotherapy techniques in recent years have allowed dose escalation with better PTV coverage, significantly improving treatment outcomes with reduced treatment associated GI toxicities. Our study demonstrated HS was well tolerated with no adverse effects associated with the device, nor any rectal complications reported in our patient cohort.

In lieu of not having a control group and comparing our HS cohort with our current institution's non HS patients, the patients receiving the HS implant had rectal dose endpoints that are much lower particularly in the high dose region $\mathrm{rV}_{78}: 0.4 \%$ vs $4.5 \% ; \mathrm{rV}_{75}: 3.6 \%$ vs $9.5 \% ; \mathrm{rV}_{70}: 7.8 \%$ vs $12.5 \% ; \mathrm{rV}_{60}: 14.4 \%$ vs $19 \%$ and $\mathrm{rV}_{50}$ : $27.3 \%$ vs $28.5 \%$. This indicated that the application of HS has considerably decreased the amount of the anterior rectal volume being treated with the mean $\mathrm{rV}_{70}$ dropping from $12.5 \%$ to $7.8 \%$ for HS patients. Our results were in accordance with other published studies ${ }^{12,14,18,19}$ and this has further validated our findings. Due to a broad range in prostate size, we also investigated the clinical benefits of $\mathrm{HS}$ in larger prostate size. Our study confirmed rectal dosimetry parameters (Fig. 3) were consistent across the cohort, demonstrating it is possible to achieve noticeable reduction in $\mathrm{rV}_{70}$ irrespective of prostate size.

We recognise that our $\mathrm{rV}_{70}$ and $\mathrm{V}_{75}$ are marginally higher (Table 6) than other studies however we attribute this finding to our contouring method. In contrast to some studies 3,14 where the rectum was contoured from the recto-sigmoid junction to the level of ischial tuberosity, our rectum was contoured from $1.0 \mathrm{~cm}$ above the PTV's upper level to the ano-rectal junction. This resulted in a smaller total rectal volume which in turn resulted in a higher relative rectal dosimetric parameter.

The relatively high reduction in the high-dose regions was the logical explanation for our decreased patient reported GI toxicities. In particular, an overall of only 16 patients (20\%) experience acute grade 1 GI toxicities, which resolved completely $(97 \%)$ at 3 months post-treatment. The remaining two patients developed either late grade 1 rectal haemorrhage $(n=1)$ or proctitis $(n=1)$ at 8 months post-treatment. No patients experienced acute or late grade $2+$ GI toxicities. $\mathrm{Uhl}^{21}$ have observed similar 
low-grade 1 GI toxicities at 12 months and no reported grade 2+ GI toxicities, whilst slightly higher acute and late GI toxicity rates were noted by $\mathrm{Uhl}^{20}$ and Whalley ${ }^{6}$.

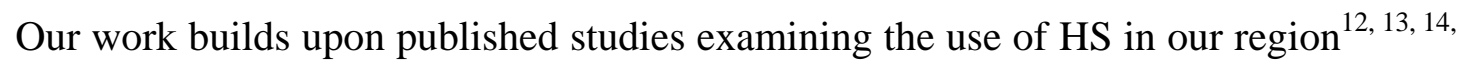
22, 23, 24. In particular, our findings are comparable to three studies ${ }^{12,13,14}$ reported on rectal dose endpoints and toxicities (late grade 1) and found them to be significantly lower across all patient groups, with the greatest difference observed in the higher rectal dose (V65 to V82) range. More recently, a study by Mariados ${ }^{18}$ examined 222 patients who were randomized with HS $(n=149)$ or without HS $(n=73)$ whilst undergoing IMRT to a dose of 79.2 Gy in 44 fractions. The authors have reported similar results to our study with no significant adverse events related to HS injection and no differences in rates of acute rectal toxicity between the HS and control groups. Another study by Pinkawa ${ }^{25}$, reported on 167 consecutive patients treated either with HS ( $n=110$ ) or without HS ( $n=66$ ) whilst undergoing prostate RT up to a maximum dose of $80 \mathrm{~Gy}$. These authors have also reported similar findings to our study that the HS injection was found to result in favourable rectal dosimetry with minimal acute rectal toxicity during and shortly after RT.

There are a few key strengths to our study that has been listed below. Firstly, our study was prospective data collection from a large cohort of patients attending a specialist radiation oncology centre in Melbourne, Australia. Secondly, we followed the directives established by the recent consensus statement on the indication and application of a HS for prostate radiotherapy ${ }^{26}$. Thirdly, we reported minimal acute adverse events during the HS implantation procedure and throughout the 12-month follow-up period. Fourthly, with a single radiation oncologist being involved in this study, we were quite confident with the level of consistency with the HS injection technique, degree of contouring and grading of toxicities. Finally, we did not have any restrictions placed on the prostate size (i.e. less than $80 \mathrm{cc}$ ) compared to other published data ${ }^{3}, 17,19,20$ which allowed analysis of the effectiveness of the hydrogel spacer in its ability to increase the peri rectal space, irrespective of prostate volume.

This study had a series of limitations which were not unique to our setting and acknowledged in other published studies that also undertook a single institution research activity using cohort or case series research designs and small sample sizes. 
Secondly, we may have missed late grade 2 GI toxicities given that toxicities were at risk of occurring 17 months (median) after treatment ${ }^{12}$. Thirdly, patients did not undergo pre- and post- imaging with CT, MRI or both to measure prostate rectum spacing and to define the volume of hydrogel inserted. Lastly, we did not record patient-centred outcomes such as health-related or disease-specific quality of life.

In conclusion, although our study was limited in its scope, the data has provided clinicians with local data about the application and benefits of HS on reducing GI toxicities during prostate cancer RT. However, if further regionally-based research is going to be conducted, studies must consider using multiple radiation oncology centres and stronger study designs that collect patient-focused clinical and nonclinical outcome measures, dosimetric regimens, long-term safety and effectiveness data that includes not only toxicity but also health-related and disease-specific quality of life measures.

\section{Conflict of interest}

The authors declare no conflict of interest.

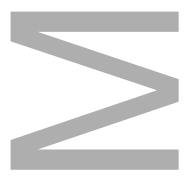

\section{References}

1. Australian Institute of Health and Welfare 2017. Cancer in Australia 2017 Cancer series no.101. Cat. no. CAN 100. Canberra: AIHW.

2. Vargas C, Martinez A, Kestin LL, Yan D, Grills I, Brabbins et al. Dosevolume analysis of predictors for chronic rectal toxicity after treatment of prostate cancer with adaptive image-guided radiotherapy. Int J Radiat Oncol Biol Phys 2005; 62:1297-1308.

3. Song DY, Herfarth KK, Uhl M, Eble MJ, Pinkawa M, van Triest B et al. A multi-institutional clinical trial of rectal dose reduction via injected polyethylene-glycol hydrogel during intensity modulated radiation therapy for prostate cancer: analysis of dosimetric outcomes. Int J Radiat Oncol Biol 
Phys. 2013 Sep 1; 87(1): 81-7.

4. Wilder RB, Barme GA, Gilbert RF, Holevas RE, Kobashi LI, Reed RR et al. Cross-linked hyaluronan gel reduces the acute rectal toxicity of radiotherapy for prostate cancer. Int J Radiat Oncol Biol Phys. 2010 Jul 1; 77(3): 824-830.

5. Noyes WR, Hosford CC, Schultz SE. Human collagen injections to reduce rectal dose during radiotherapy. Int J Radiat Oncol Biol Phys. 2012 Apr 1; 82(5): 1918-1922.

6. Morancy TJ, Winkfield KM, Karasiewicz CA, Kaplan ID. Use of a blood patch technique to reduce rectal dose during cesium-131 prostate brachytherapy. Int J Radiat Oncol Biol Phys. 2008 Sept 1: 72(1): s331-332

7. Ng M, Brown E, Williams A, Chao M, Lawrentschuk N, Chee R. Fiducial markers and spacers in prostate radiotherapy: current applications. BJU Int. 2014 March: 113 Suppl 2: 13-20.

8. Nguyen PL, Devlin PM, Beard, CJ, Orio PF, O’Leary MP, Wolfsberger LD et al. High dose rate brachytherapy for prostate cancer in a previously radiated patient with polyethylene glycol hydrogel spacing to reduce rectal doe: Case report and review of the literature. Brachytherapy. 2013 Jan: 12(1): 77-83

9. Mahal BA, Ziehr DR, Hyatt AS, Neubauer-Sugar EH, O'Farrel DA, O'Leary MP et al. Use of a rectal spacer with low-dose-rate brachytherapy for treatment of prostate cancer in previously irradiated patients: Initial experience and short term results: Brachytherapy. 2014 Sept: 13 (5): 442-449.

10. Mok G, Benz E, Vallee JP, Miralbell R, Zilli T. Optimization of radiation therapy techniques for prostate cancer with prostate-rectum spacers: a systematic review. Int J Radiat Oncol Biol Phys. 2014 Oct 1; 90 (2): 278-88.

11. Trifiletti DM, Garda AE, Showalter TN. Implanted spacer approaches for pelvic radiation therapy. Expert Rev Med Devices. 2016 Jul; 13(7): 633-40. 
12. Whalley D, Hruby G, Alfieri F, Kneebone A, Eade T. SpaceOAR Hydrogel in Dose-escalated Prostate Cancer Radiotherapy: Rectal Dosimetry and Late Toxicity. Clin Oncol (R Coll Radiol). 2016 Oct; 28(10): e148-54.

13. Te Velde BL, Westhuyzen J, Awad N, Wood M, Shakespeare TP. Can a perirectal hydrogel spaceOAR programme for prostate cancer intensity-modulated radiotherapy be successfully implemented in a regional setting? $\mathrm{J}$ Med Imaging Radiat Oncol. 2017 Feb 2. doi: 10.1111/1754-9485.12580

14. van Gysen K, Kneebone A, Alfieri F, Guo L, Eade T. Feasibility of and rectal dosimetry improvement with the use of SpaceOAR® hydrogel for doseescalated prostate cancer radiotherapy. J Med Imaging Radiat Oncol. 2014 Aug; 58(4): 511-6

15. Delahunt B, Egvad L, Grignon DJ, Srigley JR, Samaratunga H. Prostate cancer grading: recent developments and future directions. BJU Int 2016 May, 117: Supp 4: 7-8.

16. Rashid P, Gianduzzo TRJ. Urology technical and non-technical skill development: the emerging role of simulation. BJU Int 2016 May, 117: Supp 4: $9-16$.

17. Sidhom MA, Kneebone AB, Lehman M, Wiltshire KL, Millar JL, Mukherjee RK, et al Post-prostatectomy radiation therapy: Consensus guidelines of the Australian and New Zealand Radiation Oncology Genito-Urinary Group Radiother Oncol 2008; 88(1): 10-19.

18. Mariados N, Sylvester J, Shah D, Karsh L, Hudes R, Beyer D et al. Hydrogel Spacer Prospective Multicenter Randomized Controlled Pivotal Trial: Dosimetric and Clinical Effects of Perirectal Spacer Application in Men Undergoing Prostate Image Guided Intensity Modulated Radiation Therapy Int J Radiat Oncol Biol Phys. 2015 Aug 1; 92(5): 971-7. 
19. Wolf F, Gaisberger C, Ziegler I, Krenn E, Scherer P, Hruby S et al Comparison of two different rectal spacers in prostate cancer external beam ra diotherapy in terms of rectal sparing and volume consistency Radiother Oncol. 2015 Aug; 116(2): 221-5

20. Uhl M, van Triest B, Eble MJ, Weber DC, Herfarth K, De Weese TL. Low rectal toxicity after dose escalated IMRT treatment of prostate cancer using an absorbable hydrogel for increasing and maintaining space between the rectum and prostate: results of a multi-institutional phase II trial. Radiother Oncol. 2013 Feb; 106(2): 215-9

21. Uhl et al Absorbable hydrogel spacer use in men undergoing prostate cancer radiotherapy: 12-month toxicity and proctoscopy results of a prospective multicenter phase II trial. Radiother Oncol. 2014 Apr 24; 9:96

22. Beydoun N, Bucci JA, Chin YS, Malouf D, Enari E, Painter SD. First report of transperineal polyethylene glycol hydrogel spacer use to curtail rectal radiation dose after permanent iodine-125 prostate brachytherapy. Brachytherapy. 2013 Jul-Aug; 12(4): 368-74

23. Juneja P, Kneebone A, Booth JT, Thwaites DI, Kaur R, Colvill E et al. Prostate motion during radiotherapy of prostate cancer patients with and without application of a hydrogel spacer: a comparative study. Radiat Oncol. 2015 Oct $24 ; 10: 215$

24. Teh AY, Ko HT, Barr G, Woo HH. Rectal ulcer associated with SpaceOAR hydrogel insertion during prostate brachytherapy BMJ Case Rep. 2014 Dec 22; 2014

25. Pinkawa M, Berneking V, König L, Frank D, Bretgeld M, Eble MJ. Hydrogel injection reduces rectal toxicity after radiotherapy for localized prostate cancer. Strahlenther Onkol. 2017 Jan; 193(1): 22-28 
26. Müller AC, Mischinger J, Klotz T, Gagel B, Habl G, Hatiboglu G et al. Interdisciplinary consensus statement on indication and application of a hydrogel spacer for prostate radiotherapy based on experience in more than 250 patients. Radio Oncol. 2016 Jul 19; 50(3): 329-36

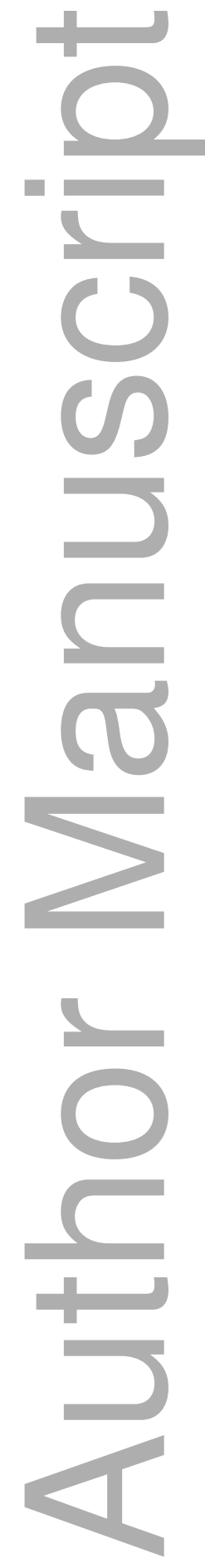




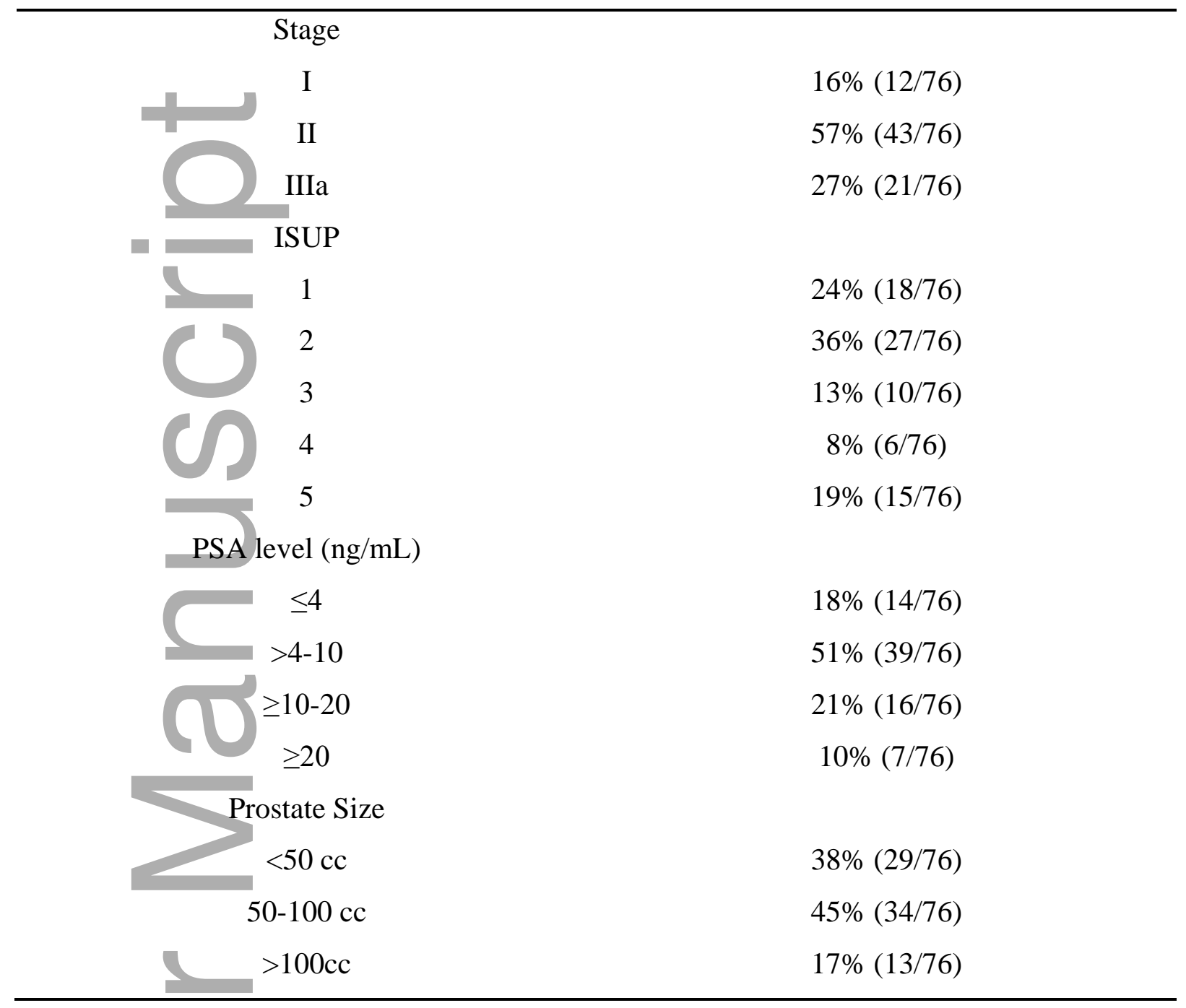


Table2. Peri-rectal spacing results

\begin{tabular}{|c|c|c|c|}
\hline Patient Cohort $(n=76)$ & Mean $( \pm$ SD), mm & Median (Range), mm & \\
\hline Base & $10.6( \pm 2.5)$ & $11(5-17)$ & \\
\hline Mid Gland & $7.7( \pm 2.1)$ & $8(4-12)$ & \\
\hline Apex & $4.9( \pm 1.9)$ & $5(1-9)$ & \\
\hline Different Prostate Size & $<50 \mathrm{cc}(\mathrm{n}=29)$ & $>50 \mathrm{cc}(\mathrm{n}=34)$ & $>100 \mathrm{cc}(\mathrm{n}=13)$ \\
\hline \multicolumn{4}{|l|}{ Base } \\
\hline $\begin{array}{l}\text { Mean }( \pm \mathrm{SD}), \mathrm{mm} \\
\text { Median (Range), mm }\end{array}$ & $\begin{array}{l}10( \pm 2.2) \\
10(5-14)\end{array}$ & $\begin{array}{l}11( \pm 2.5) \\
11(6-17)\end{array}$ & $\begin{array}{l}10.9( \pm 2.9) \\
11(7-15)\end{array}$ \\
\hline \multicolumn{4}{|l|}{ Mid-gland } \\
\hline Mean $( \pm S D), m m$ & $7.4( \pm 1.5)$ & $8.1( \pm 2.3)$ & $8( \pm 2.2)$ \\
\hline Median (Range), mm & $7(4-11)$ & $8(2-12)$ & $8(5-11)$ \\
\hline \multicolumn{4}{|l|}{ Apex } \\
\hline Mean $( \pm S D), m m$ & $5( \pm 1.4)$ & $5.1( \pm 2.1)$ & $4.5( \pm 2.1)$ \\
\hline Median (Range), mm & $5(3-8)$ & $5(3-8)$ & $5(2-8)$ \\
\hline
\end{tabular}


Table 3. Achievable Rectal Dose Constraint for HS

\begin{tabular}{lc}
\hline OAR Constraints & Hydrogel Spacer Mean (\%) \\
\hline Rectum $V 50 G y \leq 50 \%$ & 27.3 \\
Rectum $V 60 G y \leq 35 \%$ & 14.4 \\
Rectum $V 70 G y \leq 20 \%$ & 7.8 \\
Rectum $V 75 G y \leq 15 \%$ & 3.6 \\
Rectum $V 78 G y \leq 5 \%$ & 0.4 \\
\hline
\end{tabular}

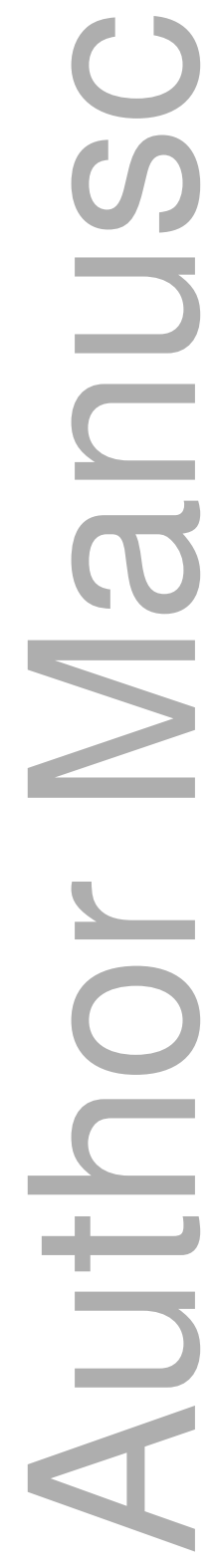

This article is protected by copyright. All rights reserved 
Table 4. Radiation induced GI toxicity

\begin{tabular}{lcc} 
& \multicolumn{2}{c}{ Overall GI Toxicity } \\
\cline { 2 - 3 } & Acute $(\mathbf{n = 7 6})$ & Late $(\mathbf{n}=\mathbf{7 5} \dagger)$ \\
Grade 0 & $60(79 \%)$ & $73(97 \%)$ \\
Grade 1 & $16(21 \%)$ & $2(3 \%)$ \\
Grade 2+ & 0 & 0 \\
\hline
\end{tabular}

†1 patient lost to follow up

(1.

$\square$

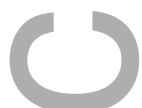

$\infty$

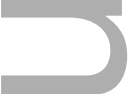

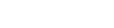
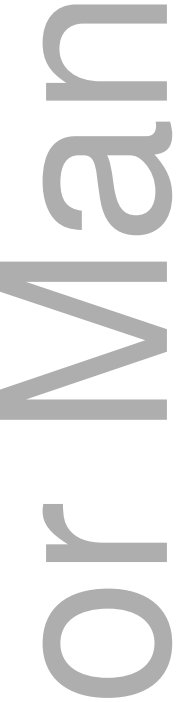

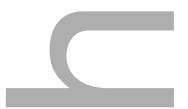
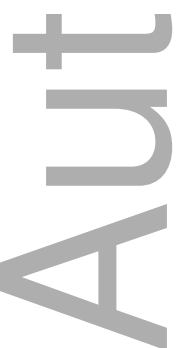

This article is protected by copyright. All rights reserved 
Table 5. Radiation induced GU toxicity

\begin{tabular}{lcc} 
& \multicolumn{3}{c}{ GU Toxicity } \\
\cline { 2 - 3 } & Acute $(\mathbf{n = 7 6})$ & Late $(\mathbf{n}=\mathbf{7 5} \dagger)$ \\
Grade 0 & $13(17 \%)$ & $57(76 \%)$ \\
Grade 1 & $63(83 \%)$ & $16(21 \%)$ \\
Grade 2+ & 0 & $2(3 \%)$ \\
\hline
\end{tabular}

†1 patient lost to follow up

(1.

○

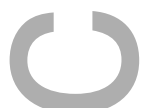

$\infty$

(
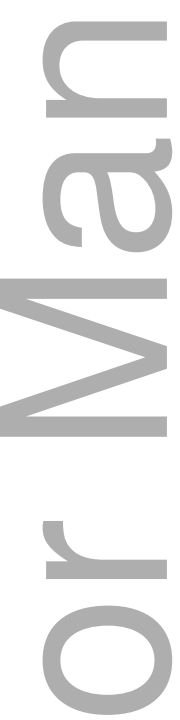

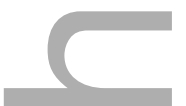
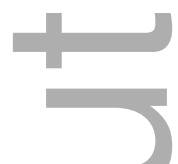

元

This article is protected by copyright. All rights reserved 
Table 6. Mean \pm SD comparing rectal dose volume

\begin{tabular}{lll}
\hline Study groups & rV70 & rV75 \\
\hline Our cohort $(\mathrm{n}=76)$ & $8.5 \pm 4.2$ & $4 \pm 2.5$ \\
Mariados $(\mathrm{n}=148)$ & $3.3 \pm 3.2$ & $0.6 \pm 0.9^{€}$ \\
Song $(\mathrm{n}=45)$ & $5.1 \pm 4.2$ & $1.2 \pm 1.3$ \\
\hline
\end{tabular}
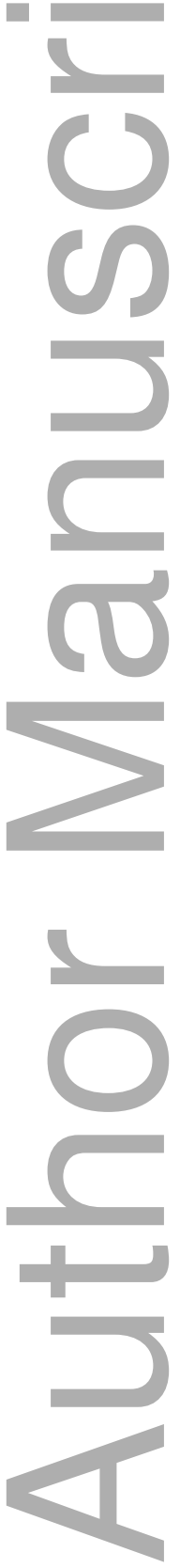

This article is protected by copyright. All rights reserved 


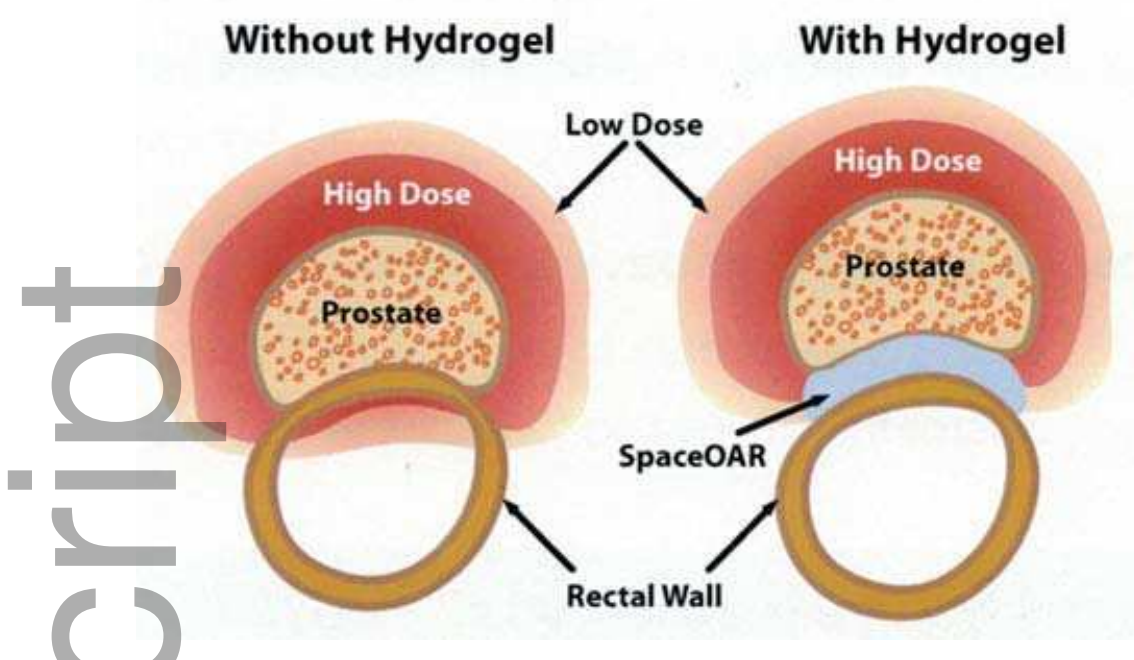

Fig 1. Insertion of $H S$ into the peri-rectal space pushing the rectum out of the high dose region.

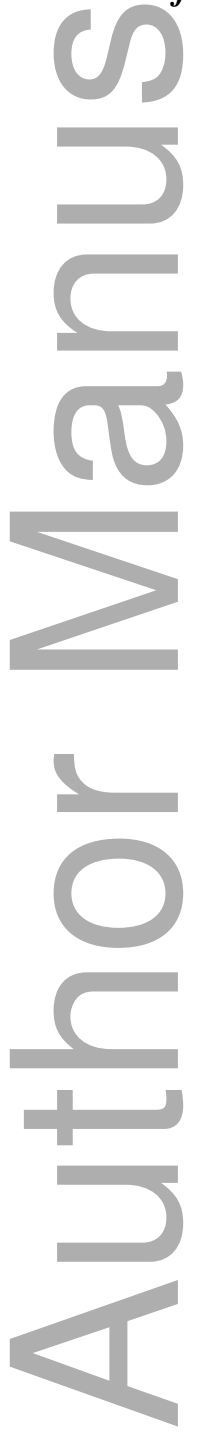

This article is protected by copyright. All rights reserved 
Figure 2. HS injection pushing the rectum out of the field significantly reduced the rectal dose

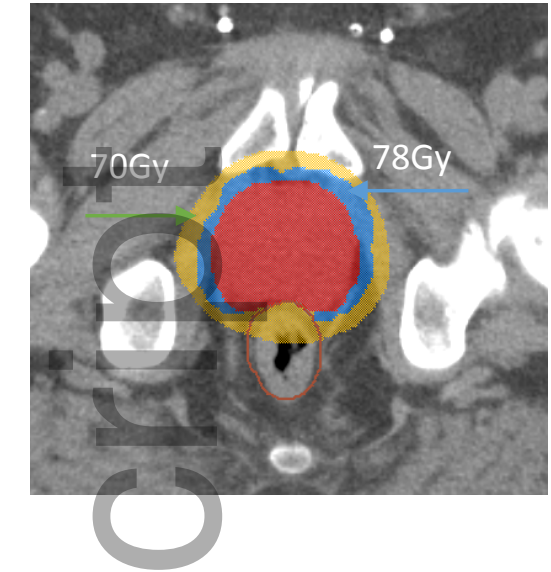

Pre Spacer Injection Axial

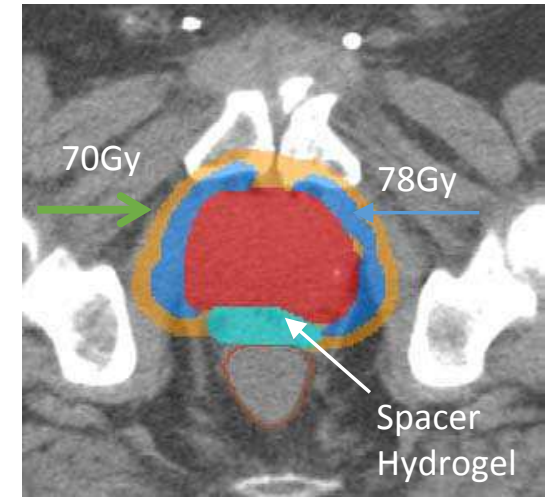

Post Spacer Injection Axial
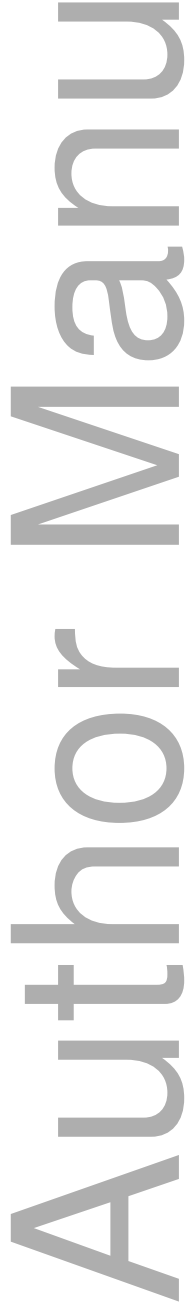

This article is protected by copyright. All rights reserved 
Figure 3. Mean rectal volume constraints (cc) for different prostate size
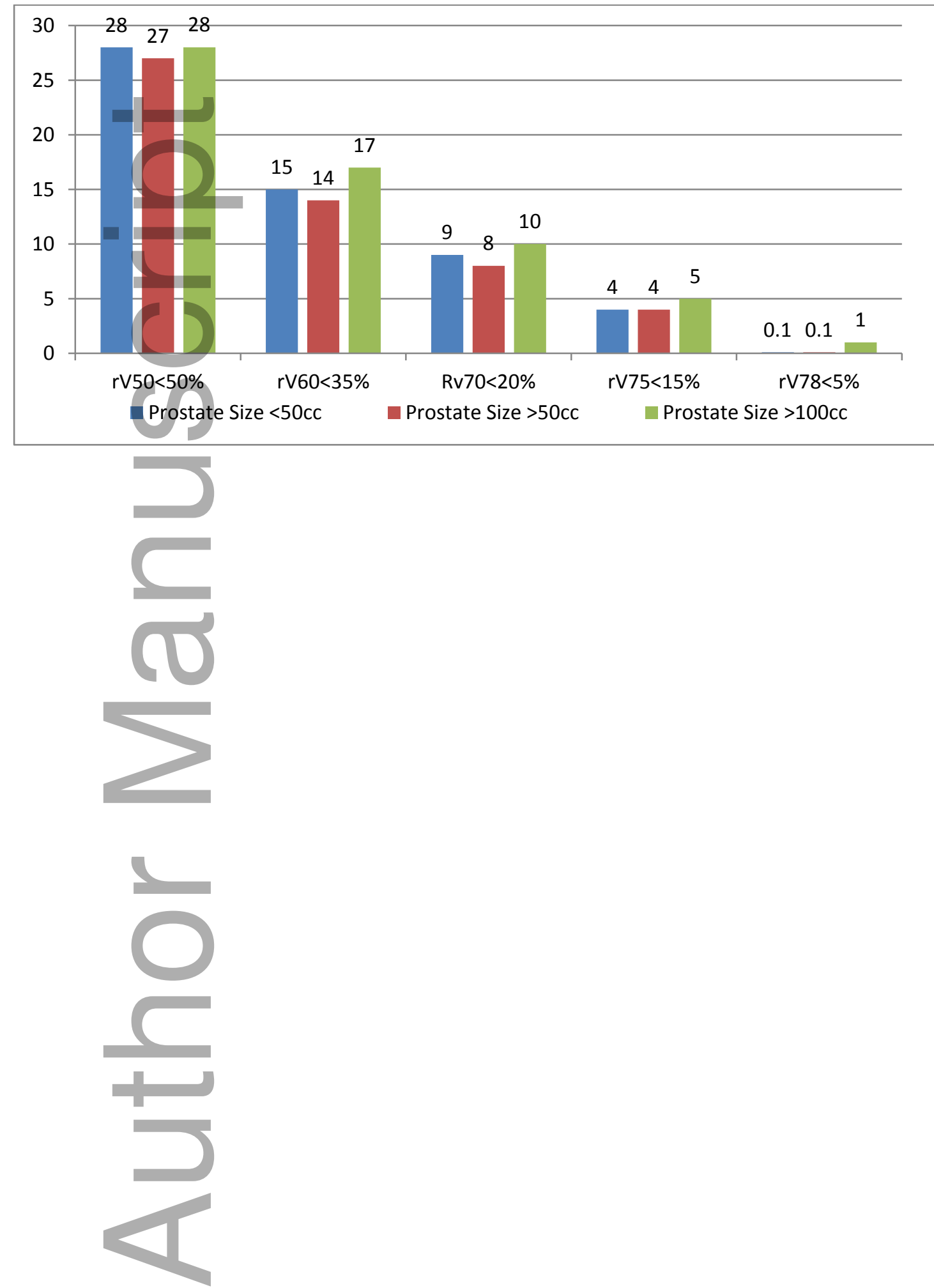

This article is protected by copyright. All rights reserved 
Figure 4. Acute GI toxicity by timepoint

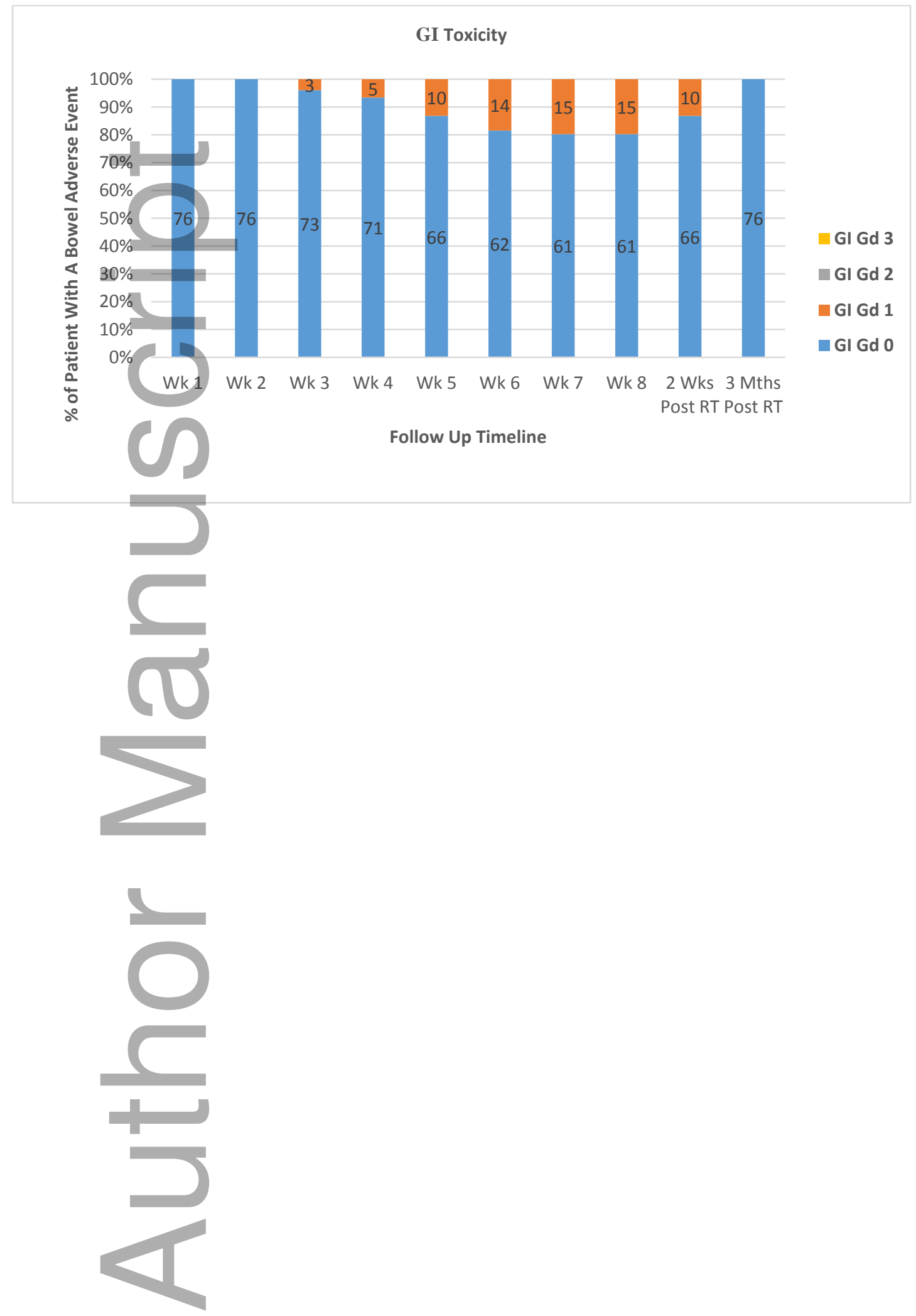

This article is protected by copyright. All rights reserved 


\section{University Library}

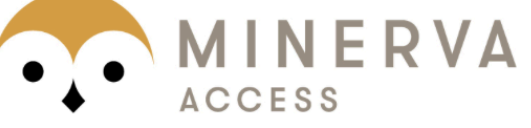

A gateway to Melbourne's research publications

Minerva Access is the Institutional Repository of The University of Melbourne

\section{Author/s:}

Chao, M;Ho, H;Chan, Y;Tan, A;Trung, P;Bolton, D;Troy, A;Temelcos, C;Sengupta, S;McMillan, K;Cham, CW;Liu, M;Ding, W;Subramanian, B;Wasiak, J;Joon, DL;Spencer, S;Lawrentschuk, $\mathrm{N}$

Title:

Prospective analysis of hydrogel spacer for patients with prostate cancer undergoing radiotherapy

\section{Date:}

2018-09-01

\section{Citation:}

Chao, M., Ho, H., Chan, Y., Tan, A., Trung, P., Bolton, D., Troy, A., Temelcos, C., Sengupta, S., McMillan, K., Cham, C. W., Liu, M., Ding, W., Subramanian, B., Wasiak, J., Joon, D. L., Spencer, S. \& Lawrentschuk, N. (2018). Prospective analysis of hydrogel spacer for patients with prostate cancer undergoing radiotherapy. BJU INTERNATIONAL, 122 (3), pp.427-433. https://doi.org/10.1111/bju.14192.

Persistent Link:

http://hdl.handle.net/11343/283850 